Research Paper

\title{
Signal transduction mechanism for glucagon-induced leptin gene expression in goldfish liver
}

\author{
Ai-fen Yan 1, Ting Chen 2,3, $₫$, Shuang Chen ${ }^{4}$, Dong-sheng Tang 1, Fang Liu 1, Xiao Jiang 2, Wen Huang ${ }^{2}$, \\ Chun-hua Ren 2,3, Chao-qun $\mathrm{Hu}^{2,3}$ \\ 1. School of stomatology and medicine, Foshan University, Foshan 528000, China. \\ 2. CAS Key Laboratory of Tropical Marine Bio-resources and Ecology (LMB); Guangdong Provincial Key Laboratory of Applied Marine Biology (LAMB), South China Sea \\ Institute of Oceanology, Chinese Academy of Sciences, Guangzhou 510301, China. \\ 3. South China Sea Bio-Resource Exploitation and Utilization Collaborative Innovation Center, Guangzhou 510275, China. \\ 4. School of Biomedical Sciences, Li Ka Shing Faculty of Medicine, University of Hong Kong, Hong Kong, China. \\ $\triangle$ Corresponding author: chan1010@scsio.ac.cn; Tel: +86-20-89023216; fax: +86-20-84451672.
}

(C) Ivyspring International Publisher. Reproduction is permitted for personal, noncommercial use, provided that the article is in whole, unmodified, and properly cited. See http://ivyspring.com/terms for terms and conditions.

Received: 2016.06.27; Accepted: 2016.10.12; Published: 2016.12.06

\begin{abstract}
Leptin is a peripheral satiety hormone that also plays important roles in energy homeostasis in vertebrates ranging from fish to mammals. In teleost fish, however, the regulatory mechanism for leptin gene expression still remains unclear. In this study, we found that glucagon, a key hormone in glucose homeostasis, was effective at elevating the leptin-Al and leptin-All transcript levels in goldfish liver via both in vivo intraperitoneal injection and in vitro cells incubation approaches. The responses of leptin-Al and leptin-All mRNA to glucagon treatment were highly comparable. In contrast, blockade of local glucagon action could reduce the basal and induced leptin-Al and leptin-All mRNA expression. The stimulation of leptin levels by glucagon was caused by the activation of adenylate cyclase $(\mathrm{AC}) /$ cyclic-AMP (cAMP)/ protein kinase A (PKA), and probably cAMP response element-binding protein (CREB) cascades. Our study described the effect and signal transduction mechanism of glucagon on leptin gene expression in goldfish liver, and may also provide new insight into leptin as a mediator in the regulatory network of energy metabolism in the fish model.
\end{abstract}

Key words: leptin, glucagon, gene expression, signal transduction, goldfish.

\section{Introduction}

Leptin, the protein product of the obese gene [1], is one of the most prominent adipose tissue-derived hormones and plays a key role in the regulation of appetite and metabolism in vertebrates ranging from fish to mammals [2-4]. In mammals, the adipose mRNA and serum protein levels of leptin are positively correlated with body adipose mass $[5,6]$. The mammalian serum leptin levels are decreased prior to the depletion of adipose tissue mass by fasting [7], rapidly restored by re-feeding [8], and increased by overfeeding [9]. A number of peptide and non-peptide hormones have been found to mediate leptin production and secretion in mammalian models. Cholecystokinin [10] and ghrelin [11], two gastrointestinal appetite-regulated hormones, are effective at stimulating leptin secretion in rats. The sexual steroid hormones estrogen and androgen may play opposite roles, which are positive and negative, respectively, in the regulation of leptin gene expression in rat fat cells [12] and human placental cells [13]. In addition, insulin is another major stimulator of leptin production and secretion in rat and mouse adipocytes [14, 15], while its homologous hormone insulin-like growth factor-I (IGF-I) may suppress leptin secretion in rats [16].

The anorexigenic effects of leptin have been described in teleost fish $[17,18]$ as well as in mammals [19]. The nutritional status is shown highly correlated to leptin levels in fish but controversial between different species [4]. Following food deprivation, the plasma leptin content and/or hepatic leptin transcript levels are elevated in rainbow trout [20], salmon [21], flounder [22], grouper [23] and minnows [24]. Re-feeding may rapidly eliminate the up-regulation of 
leptin protein and/or mRNA levels in flounder [22], grouper [23] and minnows [24] that is caused by starvation. In contrast, neither short- nor long-term fasting nor subsequent re-feeding affected the hepatic leptin expression in common carp [25], and the hepatic leptin mRNA level increased at a long time after feeding in goldfish [26]. However, the regulatory mediator that links the nutritional status and leptin level in fish is still unclear.

Glucagon is a key metabolism-regulated hormone that is produced in $\alpha$-cells of the pancreas in mammals. It works to raise the concentration of glucose in plasma, and its effect is opposite to that of insulin, which lowers the circulating glucose levels [27]. During fasting, glucagon is a primary regulator of hepatic glucose production and release [27]. The proglucagon [28] and glucagon receptor [29] cDNAs have been previously identified in goldfish. Glucagon is effective at the stimulation of glucose production in goldfish hepatocytes, and both goldfish and human glucagons can bind the goldfish glucagon receptor and activate its intracellular signal pathways [29]. In mammalian and non-mammalian species, glucagon can regulate the production and/or secretion of other hormones, e.g., ghrelin in rats [30], somatostatin in rainbow trout [31] and fibroblast growth factor in rats [32]. However, as reported in sheep, glucagon has no effects on blood leptin levels [33, 34]. To our knowledge, the effect of glucagon on leptin regulation in fish has not yet been examined previously.

Phylogenetically, the aspect of leptin genes in teleost fish is more complicated than that in mammals $[4,35]$. This is partially due to the fish-specific genome duplication (FSGD or 3R) that occurred in teleosts [36]; duplicated leptin genes (leptin-A and leptin-B) have been reported in some fish species, whereas only a single leptin gene is found in mammals $[1,4,37]$. The receptor binding affinity of fish leptin-A is higher than that of leptin-B $[38,39]$, indicating that leptin-A is the dominant form of leptin in fish. Moreover, another genome duplication event, also called tetraploidization, in cyprinids [25] and salmonids [40] resulted in up to four leptin paralogs in these species. In goldfish, two leptin genes (GenBank: FJ534535 and FJ854572) have been reported. They are both phylogenetically clustered with other Cyprinidae leptin-A and therefore named goldfish leptin-AI and leptin-AII, respectively [26, 41]. However, the leptin-B has not yet been reported in goldfish. Recombinant goldfish leptin-AI and leptin-AII protein were effective at inhibiting feeding behavior and reducing food consumption of goldfish via mediating of the transcript levels of some central appetite regulators [17]. The liver is the metabolic center in fish, and it is also the major site for leptin expression in fish [25, 42].
To date, studies on the hormonal regulation of leptin in fish remain limited, except for finding that prolactin suppresses leptin-A synthesis in tilapia [43], and the estrogen stimulates leptin-A gene expression in minnows [24]. To shed light on the regulatory mechanism of leptin in fish, using goldfish as a model, we detected the effects of glucagon on goldfish hepatic leptin-AI and leptin-AII gene expression using both an in vivo approach with intraperitoneal (IP) injection and an in vitro approach with primary hepatocyte incubation. To further elucidate the signaling mechanisms in this pathway, the functional roles of adenylate cyclase (AC), cyclic-AMP (cAMP), protein kinase A (PKA) and cAMP response element-binding protein (CREB) in gulcagon-regulated goldfish leptin mRNA expression were also examined in primary cultured hepatocytes using pharmacological approaches.

\section{Materials and Methods}

\section{Animals}

Goldfish (Carassius auratus) with body weights ranging from 25-30 $\mathrm{g}$ were acquired from local suppliers and maintained individually in $9 \mathrm{~L}$ tanks at 20-25 ${ }^{\circ} \mathrm{C}$ under a 12:12-h dark-light photoperiod with a regular feeding schedule $(1 \mathrm{~g}$ food pellets per fish, once every day at 10:00 AM) for 14 days prior to the experiments. During the process of tissue sampling, the fish were anesthetized by $0.05 \%$ tricaine methanesulfonate (MS222, Sigma) prior to be being killed by spinosectomy according to procedures approved by the Ethics Committees of the South China Sea Institute of Oceanology, Chinese Academy of Sciences.

\section{Test substances}

Human glucagon was purchased from Phoenix Pharmaceuticals. Glucagon antagonist (as reported by $[29,44]$ were synthesized by Sangon Biotech with purity $>98 \%$ as determined by analytical HPLC. The amino acid sequences of human glucagon and glucagon antagonist are listed in Supplementary table 1. For pharmacological study, IBMX, forskolin, CPT-cAMP, 8-Br-cAMP, MDL 12330A and H89 were purchased from Calbiochem, NKH477 and SQ22536 were purchased from Sigma, and KT5720 was purchased from Tocris. Test substances were prepared as $1 \mathrm{mM}$ or $10 \mathrm{mM}$ frozen stocks in small aliquots and diluted with pre-warmed culture medium to appropriate concentrations $15 \mathrm{~min}$ prior to drug treatment.

\section{Intraperitoneal injection and in vivo sample collection}

The in vivo effects of glucagon on leptin-AI and 
leptin-AII mRNA expression in goldfish livers were analyzed with an IP injection approach. After deep anesthesia with $0.05 \%$ MS222, $100 \mu \mathrm{L}$ of glucagon solution in a concentration of $300 \mathrm{ng} / \mathrm{g}$ body weight (bwt) dissolved in freshwater fish physiological saline (FFPS, [45]) was injected into the peritoneal cavity using a 23-gauge needle attached to a $1 \mathrm{~mL}$ syringe, and injection of FFPS only was used as a control. The fish were killed at $0,1.5,3,6,12$ and $24 \mathrm{~h}$ after injection, and the liver samples were collected, frozen in liquid nitrogen and stored at $-80^{\circ} \mathrm{C}$ for RNA extraction and reverse transcription.

\section{Isolation, primary culture and static incubation of goldfish hepatocytes}

The regulation of leptin-AI and leptin-AII transcript levels by glucagon was further examined in goldfish primary hepatocytes. To prepare the goldfish hepatocytes, goldfish livers $(n=5)$ was excised and washed three times in ice-cold $\mathrm{Ca}^{2+} / \mathrm{Mg}^{2+}$-free HBSS (Gibco). The liver fragments were diced to $0.5 \mathrm{~mm}$ in thickness by means of a McILwain tissue chopper (Ted Pella) and incubated in $\mathrm{Ca}^{2+} / \mathrm{Mg}^{2+}$-free HBSS with EDTA $(1 \mathrm{mM})$ at room temperature for $5 \mathrm{~min}$ and digested with $\mathrm{Ca}^{2+} / \mathrm{Mg}^{2+}$-free HBSS containing collagenase type IV $(1 \mathrm{mg} / \mathrm{mL}$, Invitrogen $)$ and DNase II $\left(0.01 \mathrm{mg} / \mathrm{mL}\right.$, Sigma) at $28{ }^{\circ} \mathrm{C}$ for $30 \mathrm{~min}$. Next, the liver fragments were mechanically dispersed into single cells by gentle pipetting. The dispersed hepatocytes were then separated from the remaining fragments by filtration through a sterile 30 $\mu \mathrm{m}$ mesh and harvested by centrifugation at $100 \times \mathrm{g}$ for $5 \mathrm{~min}$ at $4{ }^{\circ} \mathrm{C}$. The hepatocytes obtained were resuspended in DMEM/F-12 (Gibco). The viability of the cells was assessed using a Trypan blue exclusion assay and only preparations with more than 95\% viability were used in subsequent experiments. The cells were diluted to $0.4 \times 10^{6}$ cells $/ \mathrm{mL} /$ well in DMEM/F-12 and seeded onto 24 well-plates precoated with PEI ( $5 \mu \mathrm{g} / \mathrm{mL}$, Sigma), then incubated in $5 \% \mathrm{CO}_{2}$ and saturated humidity at $28^{\circ} \mathrm{C}$ overnight for recovery. On the second day after cell preparation, test substances prepared in DMEM/F12 medium were gently overlaid onto hepatocytes after the removal of old culture medium. The cells were incubated with the test substances for another 1.5 to $48 \mathrm{~h}$ for time course studies, or for $6 \mathrm{~h}$ for other dose-dependent or pharmacological studies. Finally, the cells were harvested by dissolving in TRIzol reagent (Invitrogen).

\section{Measurement of goldfish leptin-Al and leptin-All mRNA levels}

Total RNA from in vivo liver samples and in vitro hepatocytes samples was isolated by using TRIzol, digested with DNase I (Invitrogen), and reverse transcribed with a PrimeScript ${ }^{\mathrm{TM}}$ RT kit (TaKaRa). Transcriptional expression of leptin-AI and leptin-AII, leptin receptor, preproinsulin, IGF-I and IGF-II were detected using SYBR Premix Ex Taq ${ }^{\mathrm{TM}}$ II (TaKaRa) in the RotorGene RG-3000 Real-Time PCR System (Qiagen) with primers and PCR conditions as shown in Supplementary table 2. Serially diluted plasmid DNAs containing the ORF sequences for the target genes were used as the standards for the real-time PCRs. After reactions, the identity of the PCR products was routinely confirmed by analysis of melting curve. In this case, the PCR primers for leptin-AI or leptin-AII amplification were specific, without cross-interaction of the other isoform.

\section{RT-PCR for goldfish leptin-Al, leptin-All, glucagon and glucagon receptor transcripts}

For the detection of leptin-AI (FJ534535), leptin-AII (FJ854572), proglucagon (U65528) and glucagon receptor (AY584244) transcripts, cDNA samples from goldfish liver and primary hepatocytes were subjected in RT-PCRs with specific primers (listed in Supplementary table 3) for these genes, and $\beta$-actin (AB039726) was used as an internal control.

\section{Measurement of CAMP production}

After an overnight incubation, the old DMEM/F12 medium for the goldfish hepatocytes was replaced with $0.9 \mathrm{~mL}$ HHBSA medium (Gibco) supplemented with IBMX $(0.1 \mathrm{mM})$ and incubated at $28{ }^{\circ} \mathrm{C}$ for $15 \mathrm{~min}$ before adding $0.1 \mathrm{~mL}$ of $10 \times$ stock solutions of glucagon. The duration of the drug treatment was routinely fixed at $20 \mathrm{~min}$. After that, the culture medium was harvested for the measurement of cAMP release, and cellular cAMP was extracted by adding lysis buffer. The cAMP content was quantified using a Cyclic-AMP $X P^{\circledR}$ Assay Kit (Cell Signaling). cAMP production was defined as the sum of cAMP release and cellular cAMP content.

\section{Western blot of hepatocyte lysates}

For western blots, goldfish hepatocytes were seeded in PEI-coated $35 \mathrm{~mm}$ dishes at a density of $2.0 \times 10^{6}$ cells $/ \mathrm{mL} /$ well. After an overnight incubation, the culture medium was replaced with new DMEM/F12 medium containing the appropriate concentrations of test substances and cultured at 28 ${ }^{\circ} \mathrm{C}$. The glucagon incubation lasted from 0 to $240 \mathrm{~min}$, and for other pharmacological studies, the treatment time was fixed at $30 \mathrm{~min}$. After that, the cells were rinsed with PBS ( $\mathrm{pH}$ 7.4) and cell lysate were prepared in RIPA buffer (Sangon Biotech) with complete protease and phosphatase inhibitor cocktails (Roche). The cell lysates were resolved on a $15 \%$ gel 
by SDS-PAGE and transblotted onto a PVDF membrane (Roche) at $20 \mathrm{~V}$ for $1 \mathrm{~h}$ with a Trans-Blot SD Electrophoretic Cell (Bio-Rad). The membrane was then blocked with 3\% BSA in TBST (Sangon Biotech) and incubated overnight at $4{ }^{\circ} \mathrm{C}$ with antibodies for phospho-CREB (1:500, Abcam), total CREB (1:500, Abcam) and $\beta$-actin (1:2000, Sangon Biotech). On the following day, HRP-conjugated goat anti-rabbit or rabbit anti-mouse IgG (1:2000, Calbiochem) was added and Immobilon Western (Pierce) was used as a HRP substrate for signal development.

\section{Data transformation and statistical analysis}

For mRNA expression, the raw data were expressed in terms of fmol target transcript per tube, and then were routinely normalized as the ratio of target gene to $\beta$-actin mRNA detected in the same sample. Given that no significant differences were noted for $\beta$-actin mRNA expression in our experiments, the raw data were simply transformed as a percentage of the mean values in the control group for statistical analysis. The data expressed as mean \pm SE and were analyzed by using one-way ANOVA followed by Fisher's least significant difference (LSD) test with SPSS (IBM Software).

\section{Results}

\section{In vivo regulation of leptin-Al and leptin-All transcripts by glucagon in goldfish livers}

To investigate the effect of glucagon on leptin gene expression in goldfish liver, the approach of IP injection was used. Glucagon mediated a time-dependent increase in hepatic leptin-AI (Fig. 1A) and leptin-AII (Fig. 1B) transcript expression. The maximal stimulatory responses for leptin-AI and leptin-AII mRNA to glucagon administration were

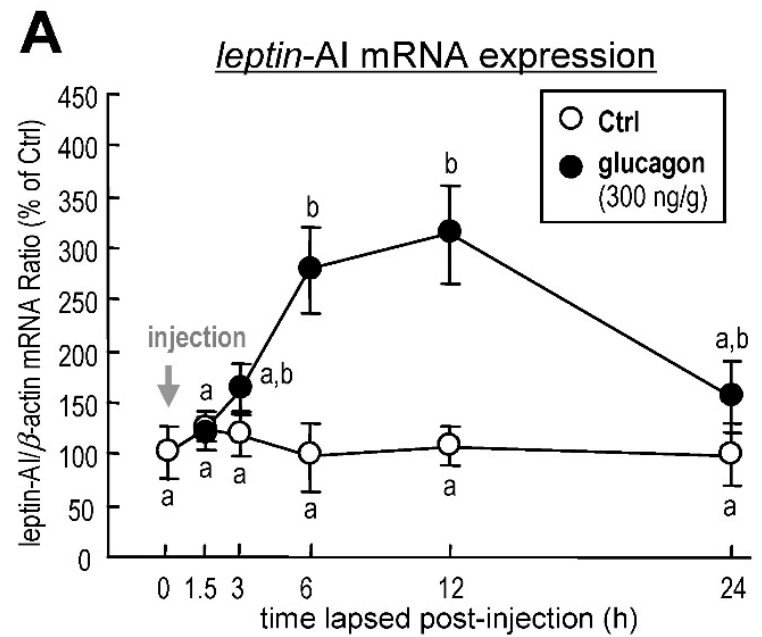

observed at $12 \mathrm{~h}$ ( 3.1-fold) and $6 \mathrm{~h}$ ( 3.9-fold), respectively.

\section{In vitro regulation of leptin-Al and leptin-All transcripts by glucagon in goldfish primary hepatocytes}

To further confirm whether the regulation of leptin expression was directly affected by glucagon, glucagon was routinely added to goldfish primary hepatocytes for static incubation. Similarly, in in vitro primary cell culture, the basal levels of leptin-AI and leptin-AII mRNA were stimulated by glucagon administration in time-dependent manners (Fig. 2A). The maximal effects of glucagon on mRNA expression for both genes were observed at $6 \mathrm{~h}$ after treatment. Additionally, increasing concentrations of glucagon could elevate transcriptional levels of leptin-AI and leptin-AII in dose-dependent manners (Fig. 2B), and the maximal responses to glucagon for both leptin isoforms were observed with a dose of $1000 \mathrm{nM}$. In parallel experiments, high dosage (1000 $\mathrm{nM}$ ) of glucagon treatment significantly reduced the mRNA levels of leptin receptor and preproinsulin, but showed no effect on IGF-I and IGF-II transcripts (Fig. $2 \mathrm{C})$.

\section{Blockade of local glucagon action on leptin-Al and leptin-All mRNA expression}

Using RT-PCR, the transcripts for leptin-AI, leptin-AII, proglucagon and glucagon receptor could be detected in goldfish livers and primary hepatocytes samples (Fig.3A). Additionally, incubation with a glucagon antagonist $(1 \mu \mathrm{M})$ could reduce the basal mRNA levels of leptin-AI and leptin-AII, and abolish the increases in both genes induced by glucagon treatment (Fig. 3B).

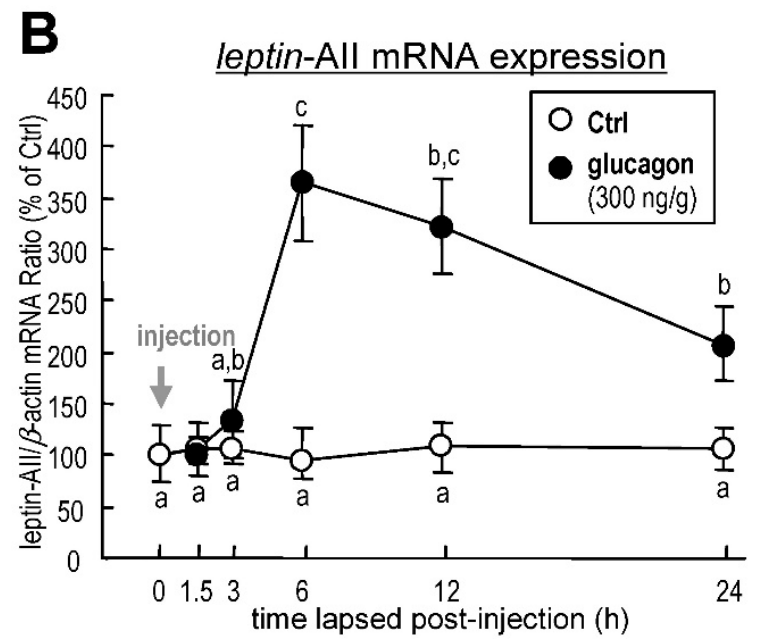

Figure 1. Changes in leptin-Al (A) and leptin-All (B) mRNA expression in goldfish liver after IP injection of glucagon ( $300 \mathrm{ng} / \mathrm{g}$ bwt) at selected time points (0, 1.5, 3, 6, 12 and 24 h). In this study, the expression level at time 0 was used as the control group, and real-time PCR for $\beta$-actin was used as the internal control. The data obtained ( $=10$ ) at various time points were then normalized as a percentage of the control group at time $0 \mathrm{~h}$. The same letter represents a similar level of transcriptional expression $(P>0.05)$, and the different letter represents significant difference in levels of transcriptional expression between two groups $(P<0.05)$. 


\section{Involvement of AC in glucagon-induced leptin-Al and leptin-All expression}

To examine the functional role of adenylate cyclase (AC) in glucagon-induced leptin-AI and leptin-AII gene expression, goldfish hepatocytes were incubated with increasing concentrations of the $\mathrm{AC}$ activator forskolin (1-100 nM) or NKH477 (1-100 nM).
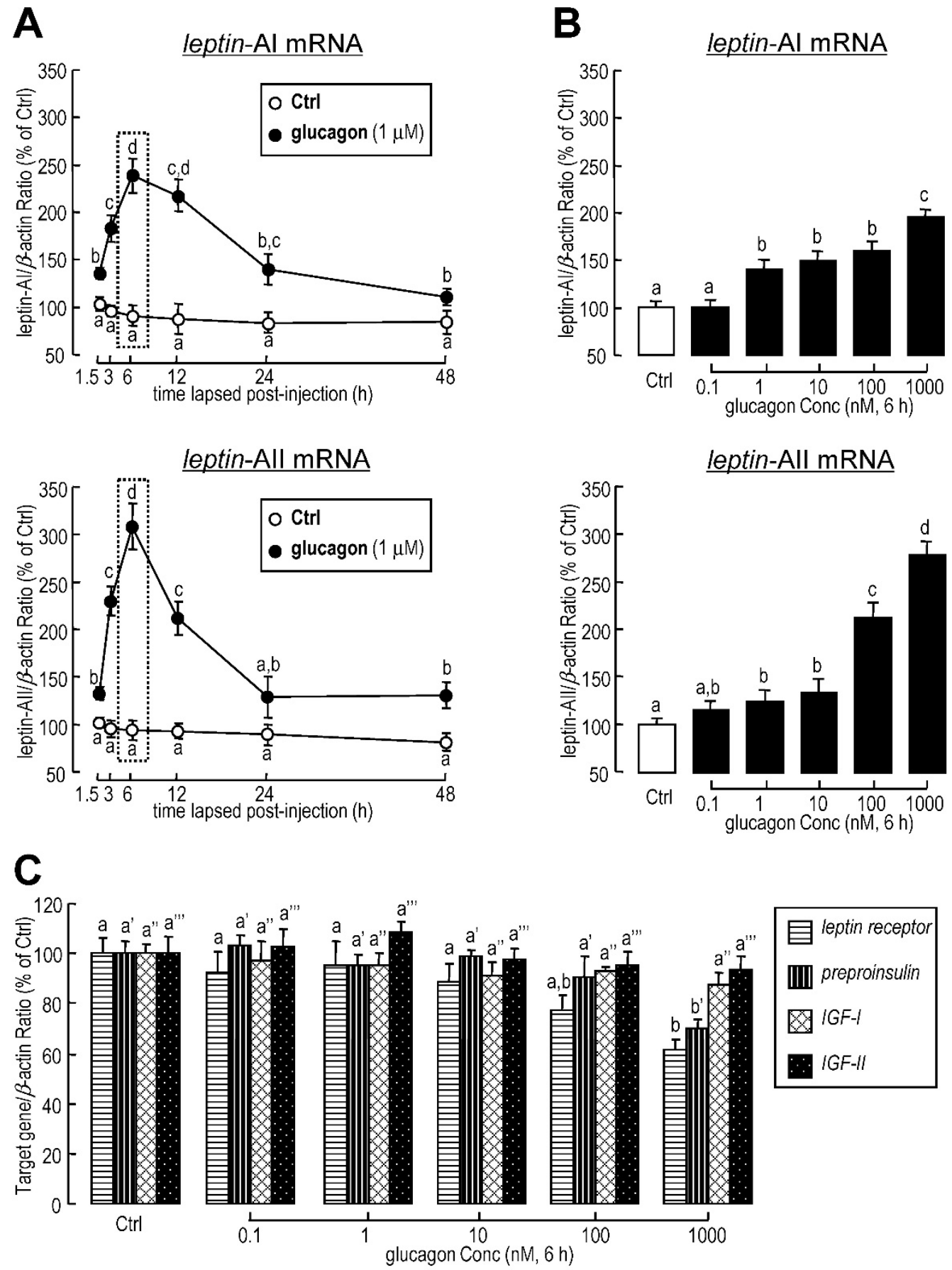

Figure 2. Effects of glucagon treatment on leptin-Al and leptin-All transcripts in goldfish primary hepatocytes. A: Time course of glucagon treatment on leptin-Al and leptin-All mRNA expression in goldfish hepatocytes culture. Using static incubation, hepatocytes were exposed to human glucagon $(1 \mu M)$ for the time indicated. The data obtained ( $\mathrm{n}=4)$ at various time points were then normalized as a percentage of the control group at time $1.5 \mathrm{~h}$. B: Dose-dependent effects of glucagon treatment on leptin-Al and leptin-All mRNA expression in goldfish hepatocyte culture. C: Dose-dependent effects of glucagon treatment on leptin receptor, preproinsulin, IGF-I and IGF-II mRNA expression in goldfish hepatocyte culture. Goldfish hepatocyte cultures were incubated for $6 \mathrm{~h}$ with increasing levels of human glucagon $(0.1-1000 \mathrm{nM})$. The data obtained ( $=4)$ with various concentrations of glucagon treatment were then normalized as a percentage of the control groups without glucagon. The same letter represents a similar level of transcriptional expression $(P>0.05)$, and the different letter represents significant difference in levels of transcriptional expression between two groups $(P<0.05)$. 
A

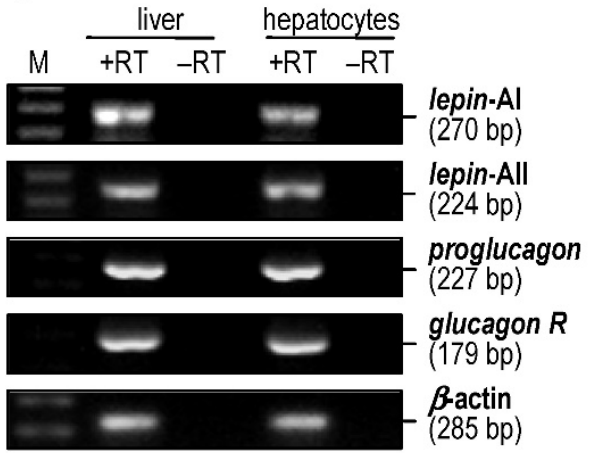

B

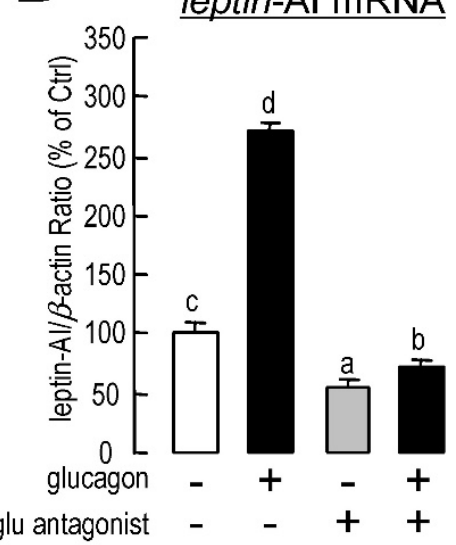

leptin-All mRNA

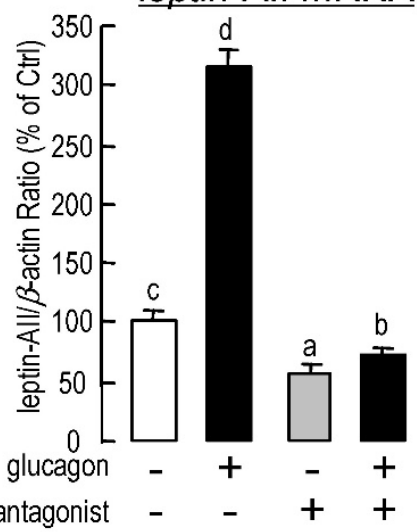

Figure 3. Autocrine/paracrine actions of glucagon on leptin-Al and leptin-All transcripts in goldfish liver. A: Detection of leptin-AI, leptin-All, proglucagon and glucagon receptor transcripts in goldfish livers. cDNA samples from goldfish livers and primary hepatocytes were used for detection and RNA samples reverse transcribed without the enzyme were used as negative controls. B: Effects of glucagon antagonist on glucagon-stimulated leptin-Al and leptin-All mRNA expression in goldfish hepatocyte cultures. The hepatocytes were incubated for $6 \mathrm{~h}$ with glucagon $(1 \mu \mathrm{M})$ in the presence or absence of glucagon antagonist $(1 \mu \mathrm{M})$. In this study, the data presented are expressed as the mean $\pm \mathrm{SE}$ ( $\mathrm{n}=4$ ). The same letter represents a similar level of transcriptional expression $(P>0.05)$, and the different letter represents significant difference in levels of transcriptional expression between two groups $(P<0.05)$.
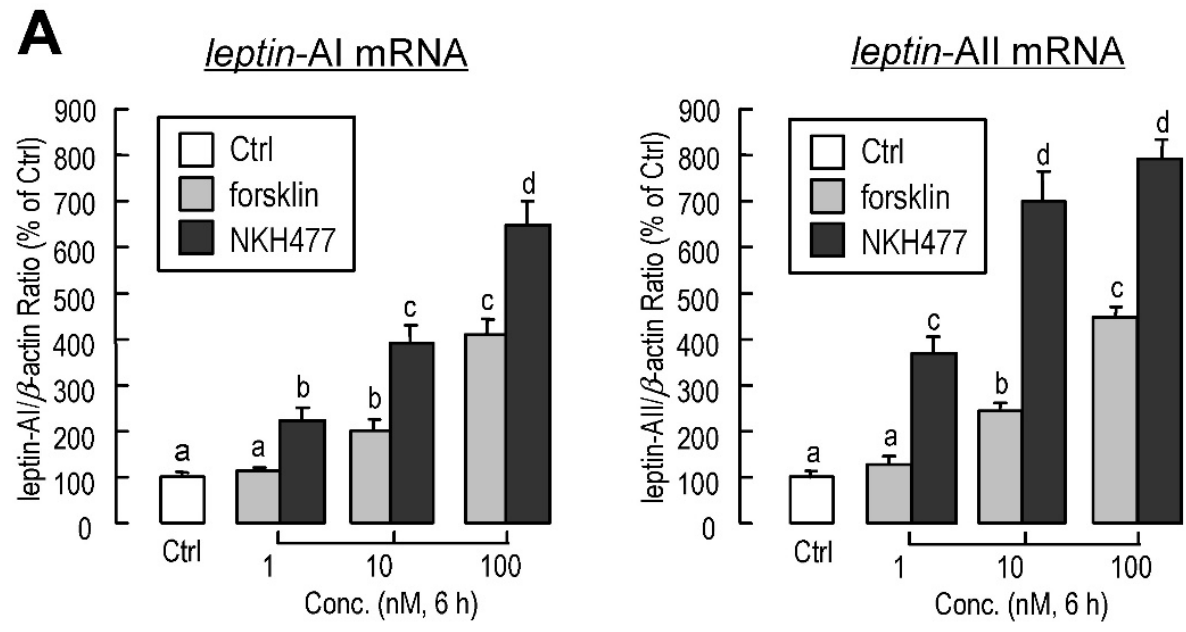

B
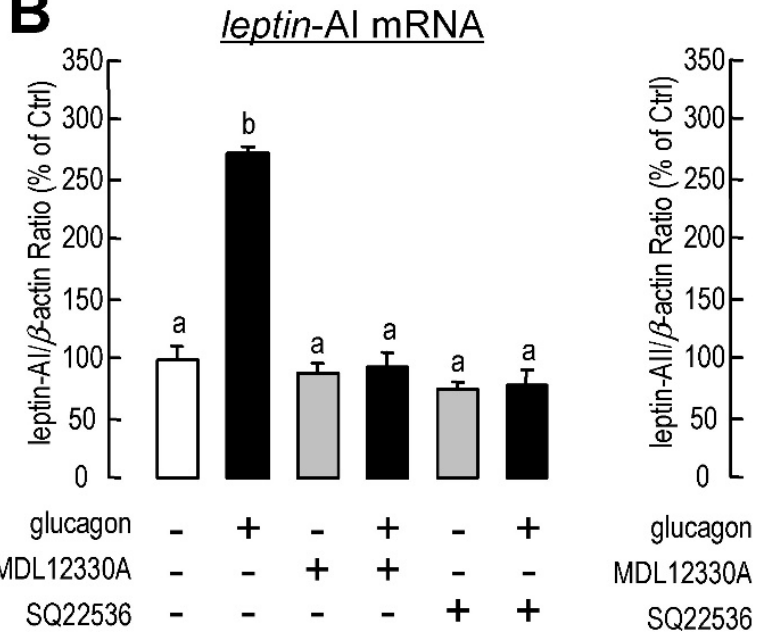

leptin-All mRNA

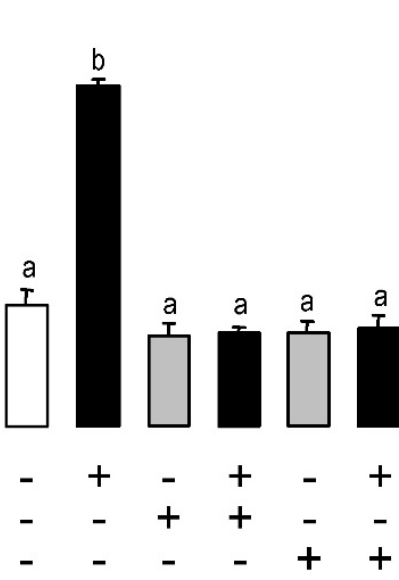

Figure 4. Involvement of AC in glucagon-induced leptin-Al and leptin-All expression in goldfish livers. A: Effects of AC activators on leptin-Al and leptin-All mRNA expression in goldfish hepatocyte cultures. The hepatocytes were incubated for $6 \mathrm{~h}$ with increasing doses of forskolin (1-100 nM) or NKH477 (1-100 nM). B: Effects of AC inhibitors on glucagon-stimulated leptin-Al and leptin-All mRNA expression in goldfish hepatocyte cultures. The hepatocytes were incubated for $6 \mathrm{~h}$ with glucagon ( $1 \mu \mathrm{M})$ in the presence or absence of MDL12330A $(20 \mu \mathrm{M})$ or SQ22536 $(50 \mu \mathrm{M})$. In this study, the data presented are expressed as the mean $\pm S E(n=4)$. The same letter represents a similar level of transcriptional expression $(P>0.05)$, and the different letter represents significant difference in levels of transcriptional expression between two groups $(P<0.05)$. 

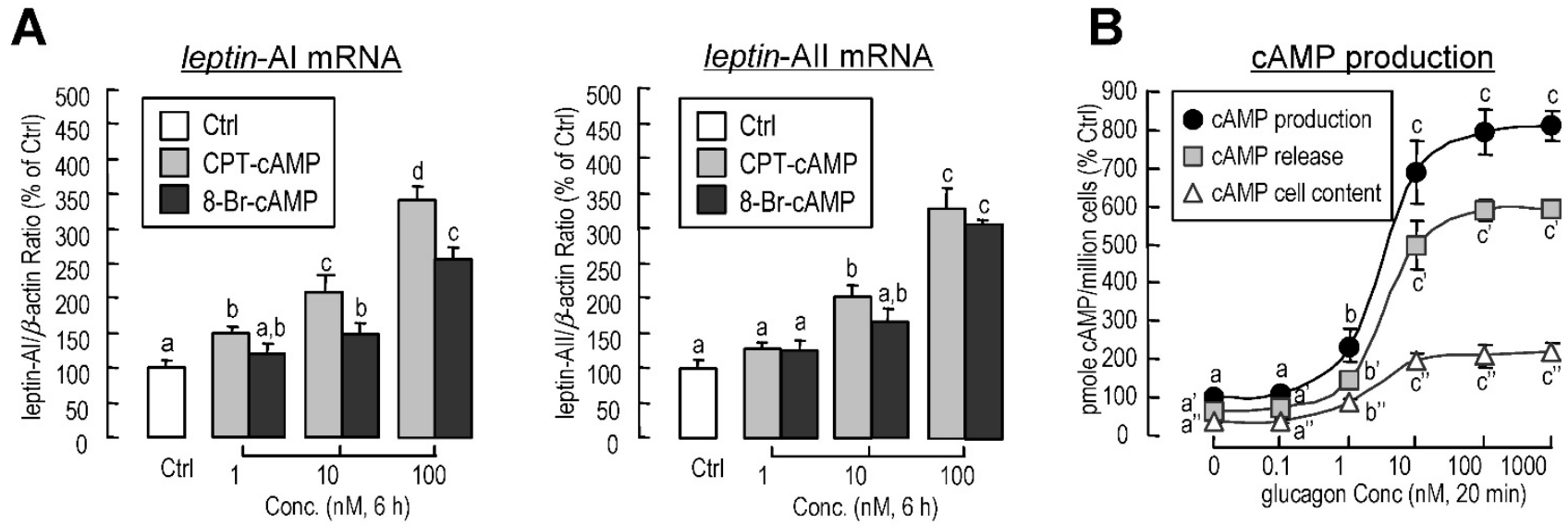

Figure 5. Involvement of cAMP in glucagon-induced leptin-Al and leptin-All expression in goldfish livers. A: Effects of cAMP analogs on leptin-AI and leptin-All mRNA expression in goldfish hepatocyte cultures. The hepatocytes were incubated for $6 \mathrm{~h}$ with increasing doses of CPT-cAMP (1-100 nM) or 8-Br-cAMP (1-100 nM). B: Effects of glucagon on cAMP release, cellular CAMP content, and total cAMP production in goldfish primary hepatocytes. The hepatocytes pretreated with IBMX (0.1 mM) were then incubated for 20 min with increasing doses of glucagon $(0.1-1000 \mathrm{nM})$. In this study, the data presented are expressed as the mean $\pm S E$ ( $n=4$ and 3 for mRNA and cAMP measurement, respectively). The same letter represents a similar level of transcriptional expression $(P>0.05)$, and the different letter represents significant difference in levels of transcriptional expression between two groups $(P<0.05)$.

\section{Involvement of cAMP in glucagon-induced leptin-Al and leptin-All expression}

To determine the participation of cyclic-AMP (cAMP) in glucagon-induced leptin-AI and leptin-AII mRNA expression, goldfish hepatocytes were incubated with increasing concentrations of the membrane-permeant cAMP analog CPT-cAMP (1-100 $\mathrm{nM})$ or 8 -Br-cAMP (1-100 nM). In this case, both CPT-cAMP and 8-Br-cAMP could elicit leptin-AI and leptin-AII mRNA expression in a dose-dependent manner (Fig. 5A). In addition, increasing concentration of glucagon was effective at stimulating cAMP release, cAMP cell content, and total cAMP production in goldfish hepatocytes in a dose-dependent manner (Fig. 5B).

\section{Involvement of PKA and CREB in glucagon- induced leptin-Al and leptin-All expression}

The involvement of protein kinase A (PKA) and cAMP-response element binding protein (CREB)-related signal pathways in leptin-AI and leptin-AII regulation in goldfish hepatocytes was also evaluated in this study. Following co-incubation with the PKA inhibitor H89 $(20 \mu \mathrm{M})$ or KT5720 $(60 \mathrm{nM})$, the stimulatory effects of glucagon on leptin-AI and leptin-AII mRNA expression were abolished (Fig. 6A). On the other hand, glucagon was effective at triggering the phosphorylation of CREB in a time-dependent manner without affecting the total CREB content (Fig. 6B), and this stimulatory effect could be mimicked by incubation with the AC activator forsklin (1-100 nM) or the cAMP analog CPT-cAMP (1-100 nM, Fig. 6C), but blocked by co-treatment with the AC inhibitor MDL12330A (20 $\mu \mathrm{M})$ or the PKA inhibitor H89 (20 $\mu \mathrm{M}$, Fig. 6D).

\section{Discussion}

In mammals, the hyperglycemia-derived hormone insulin is one of the major stimulators for leptin production and secretion [15, 46]. In contrast, our current study showed that the hypoglycemia-derived hormone glucagon could induce leptin gene expression in goldfish. It is well known that glucagon and insulin exert opposite effects on serum glucose level through the differential regulation of glycogenolysis and gluconeogenesis [27]. The circulating insulin level has been found to increase with high serum glucose levels and decrease with low serum glucose levels, while the circulating glucagon level acts opposite to the insulin level [47]. The opposite regulatory mechanism for leptin gene expression between mammals and fish may be contributed by the fundamental difference in the metabolism system between endothermic and ectothermic vertebrates. Very interestingly, incubation of insulin or its paralog hormones, IGF-I and IGF-II, may suppress leptin mRNA level in the goldfish hepatocytes (Yan et al. unpublished data), suggesting that glucagon and insulin also exert opposite effects on leptin gene expression in this Cyprinidae species. In fish, leptin has been considered more as a metabolic regulator than a satiety factor. In tilapia, leptin may convert the hepatic glycogen into plasma glucose [48]. In leptin receptor knockout medaka, largely deposits of visceral fat were observed [49]. In leptin-A knockdown zebrafish embryos, the metabolic rate and oxygen consumption are significantly lower than in un-treated embryos [50]. In leptin receptor knockout zebrafish, it has been shown that leptin is not required for adipostasis, food intake, or reproduction, but retains a role in the regulation of 
glucose homeostasis [51]. Additionally, the mRNA levels of insulin and glucagon are higher in leptin receptor-deficient zebrafish [51], implying an important link between leptin and the insulin/glucagon-controlled glucose homeostasis system.

Due to genome/single gene duplication events, teleost fish possess more abundant leptin genes than mammals. There is only one leptin gene in mammals, whereas duplicated leptin genes, namely leptin-A and leptin-B, have been identified in at least the Beloniformes, Cypriniformes, Salmoniformes and Perciformes lineages in fish [4]. In addition, the tetraploidization events within the carp and salmon genomes are likely the events that, independently from one another, gave rise to paralogous leptin-AI and leptin-AII in these species $[25,40]$. The amino acid sequence homology shared between leptin-A and leptin-B are very low, e.g., $24.5 \%$ in zebrafish [37], $17.1 \%$ in medaka [52], and $19.5 \%$ in tilapia [39]. Likewise, the regulatory modules for fish leptin-A and leptin-B gene expression are distant. In grouper, only leptin-A, but not leptin-B, hepatic mRNA levels may increase after fasting [23]. In minnows, estrogen administration induced only leptin-A, but not leptin-B, hepatic mRNA expression [24]. In contrast, the amino acid sequence homology shared between leptin-AI and leptin-AII are much higher, e.g., $82.0 \%$ in
A
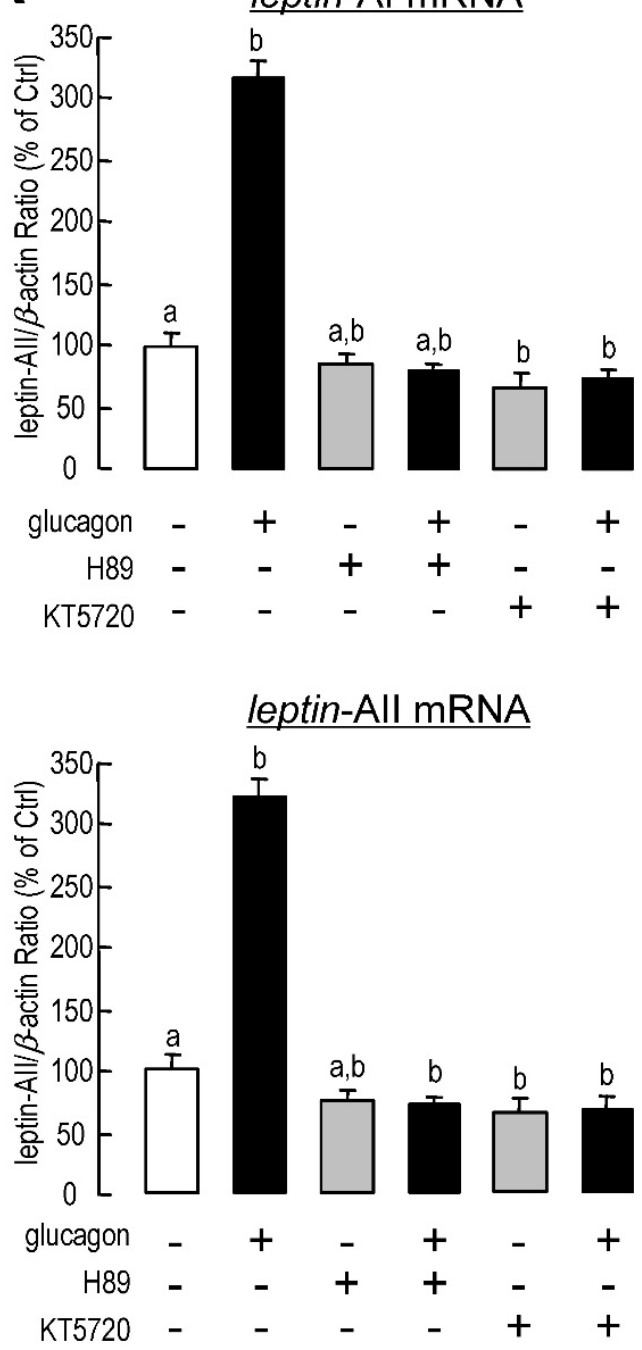

B

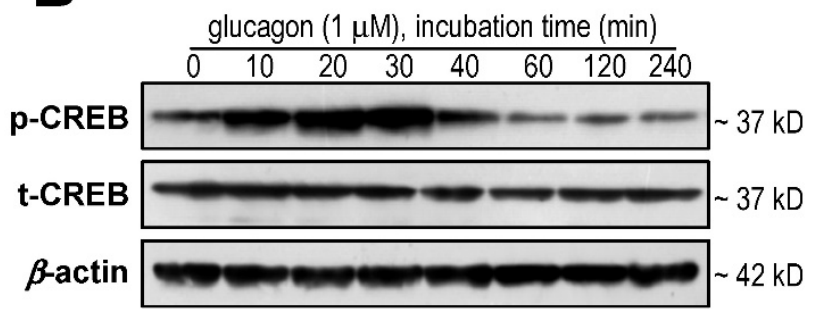

C

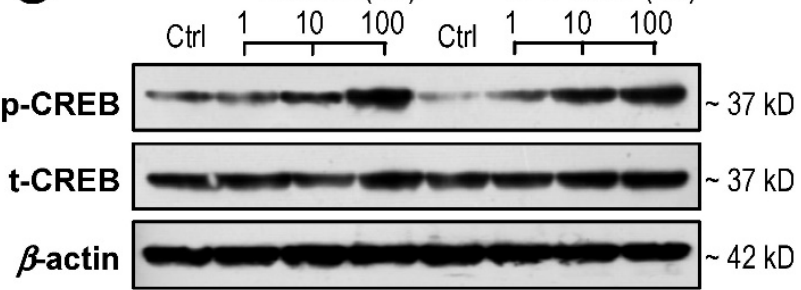

D

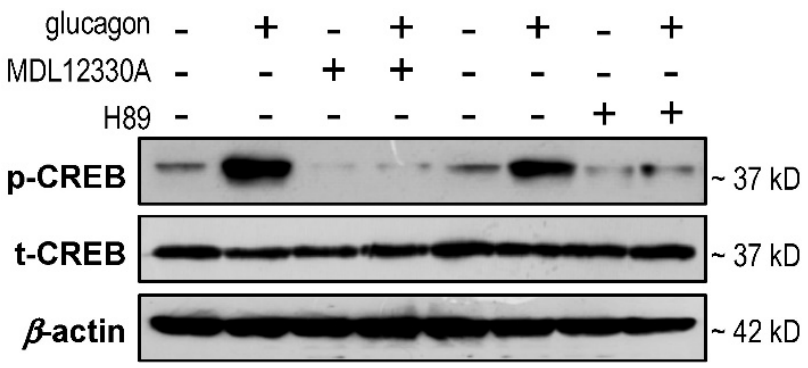

Figure 6. Involvement of PKA and CREB in glucagon-induced leptin-Al and leptin-All expression in goldfish livers. A: Effects of PKA inhibitors on glucagon-stimulated leptin-Al and leptin-All mRNA expression in goldfish hepatocyte cultures. The hepatocytes were incubated for $6 \mathrm{~h}$ with glucagon $(1 \mu \mathrm{M})$ in the presence or absence of H89 ( $20 \mu \mathrm{M})$ or KT5720 $(60 \mathrm{nM})$. In this study, the data presented are expressed as the mean \pm SE $(n=4)$. The same letter represents a similar level of transcriptional expression $(P>0.05)$, and the different letter represents significant difference in levels of transcriptional expression between two groups $(P<0.05)$. B: Glucagon-induced phosphorylation of $C R E B$ in goldfish hepatocytes. The hepatocytes were treated with glucagon $(1 \mu \mathrm{M})$ for $0,10,20,30,40,60,120$ or 240 min. C: Effects of an AC activator and cAMP analog on the phosphorylation of CREB in goldfish hepatocytes. The hepatocytes were incubated for 30 min with increasing doses of forskolin (1-100 nM) or CPT-cAMP (1-100 nM). D: Blockade of $A C$ or PKA on glucagon-induced CREB phosphorylation in goldfish hepatocytes. The hepatocytes were incubated for 30 min with glucagon ( $1 \mu M$ ) in the presence or absence of MDL12330A $(20 \mu \mathrm{M})$ or H89 $(20 \mu \mathrm{M})$. Cell lysates prepared for western blot were incubated with the antisera for phosphorylated and total CREB, and parallel blotting of $B$-actin was used as an internal control. 
common carp [25], and 79.5\% in goldfish. Previously studies showed that the anorexigenic effects of goldfish leptin-AI and leptin-AII in were highly comparable [17]. Our present study shows that the regulatory modules for goldfish leptin-AI and leptin-AII gene expression are also similar. The divergence of leptin-A and leptin-B is due to the FSGD approximately 296 million years ago (Mya, [53]), while the leptin-AI and leptin-AII differentiation due to the Cypriniformes genome tetraploidization is estimated to have occurred more recently ( $\sim 16$ Mya, [54]). Therefore, it is speculated that the regulatory modules change between leptin-A and leptin-B during evolution, whereas they remain conserved between leptin-AI and leptin-AII.

The liver is one of the most abundant sites for leptin expression in goldfish [26], and it is also the metabolic center in fish [55]. Glucagon is mainly produced in the gallbladder and intestine of goldfish [28], but its high expression signal could also be detected in the liver (Fig. 3A). Both goldfish and human glucagon display high affinity toward the goldfish glucagon receptor and are able to activate its intracellular signaling [29, 56]. The present study shows that glucagon is effective at stimulating goldfish hepatic leptin gene expression, and blockade of the endogenous glucagon by its antagonist could suppress the basal and glucagon-induced leptin-AI and leptin-AII mRNA levels (Fig. 3B). The opposite effects by glucagon blockade also prove that glucagon is a stimulator for leptin-AI and leptin-AII gene expression in goldfish liver. In addition, glucagon treatment reduced the goldfish hepatic preproinsulin mRNA level (Fig. 2C), similar to that previously reported in the rat pancreatic $\beta$-cells [57]. Glucagon administration also suppressed the expression of leptin receptor transcript (Fig. 2C), and it is possible a mechanism for eliminating the local actions of the increased leptin. However, given that leptin receptor mRNA is predominant expressed in the central nervous system but not liver, how glucagon mediating the leptin signaling is still need to be investigated. Combined with our results, the metabolic hormones insulin, glucagon and leptin may serve as a regulatory network in the goldfish liver to respond different nutrient status.

The molecular mechanisms for glucagon in teleosts are mainly focused on its functions in gluconeogenesis and glycogenolysis [58, 59]. However, the glucagon-mediated signal transduction pathways responsible for leptin gene expression are totally unknown. Therefore, we further investigated this question in goldfish hepatocytes using pharmacological approaches. The glucagon receptor is a member of the class-B G-protein coupled receptors (G-PCR) with high expression levels in the goldfish livers [29]. Major consequences of glucagon binding to the glucagon receptor include the stimulation of AC activity, the production of intracellular cAMP and the subsequent activation of PKA and phosphorylation of CREB [27]. The cell signaling events following the activation of glucagon receptor in fish species is well documented to be coupled to the AC/cAMP/PKA cascades $[29,56]$. In this study, the induction of goldfish hepatic leptin-AI and leptin-AII mRNA expression by glucagon could be mimicked by activating $\mathrm{AC}$ with its activator forskolin (Fig. 4A), and by blockade via co-treatment of the AC inhibitor MDL12330A (Fig. 4B), indicating the functional role of $\mathrm{AC}$ in glucagon-regulated leptin genes expression. In addition, cAMP, the down-stream signaling element of $\mathrm{AC}$, was observed during glucagon-induced leptin genes expression. The involvement of AC and CAMP was supported by the result that cAMP production in goldfish hepatocytes could be elevated dose-dependently with glucagon treatment (Fig. 5B), and incubation of the membrane-permeant cAMP analog CPT-cAMP was effective at up-regulating leptin-AI and leptin-AII mRNA levels (Fig. 5A). Furthermore, the PKA inhibitor H89 abolished the stimulatory effects of glucagon on leptin-AI and leptin-AII mRNA expression (Fig. 6A), indicating that PKA is critical for the glucagon-mediated stimulation of leptin genes expression. On the other hand, glucagon treatment could trigger the phosphorylation of CREB in goldfish hepatocytes (Fig. 6B), and this phosphorylation could be mimicked by the AC activator forskolin and cAMP analog CPT-cAMP (Fig. 6C), but was abolished by co-treatment of the AC inhibitor MDL12330A or the PKA inhibitor H89 (Fig. 6D), indicating that $\mathrm{AC} / \mathrm{cAMP} / \mathrm{PKA}$ is an up-stream element of glucagon-induced CREB phosphorylation. Thus, CREB is probably a transcription factor for glucagon-induced leptin-AI and leptin-AII gene expression. Given that the time of glucagon action on leptin mRNA expression is much longer than that on CREB phosphorylation, there may be a more complicated mechanism for leptin gene transcription than that initiated by CREB, but further confirmation using promoter assay is needed. These results, as a whole, suggest that the AC/cAMP/PKA cascades, and probably CREB, may play a key role in the glucagon-mediated induction of leptin gene expression in the goldfish liver, as shown in Fig. 7.

In summary, we demonstrated using in vivo and in vitro approaches that glucagon stimulates leptin-AI and leptin-AII gene expression in goldfish liver. The responses of leptin-AI and leptin-AII to glucagon treatment are highly comparable, and blockade of 
local glucagon action could reduce the basal and induced leptin-AI and leptin-AII mRNA expression. The stimulatory effects of glucagon on goldfish leptin gene expression are mediated by the intracellular AC/cAMP/PKA and probable CREB cascades (Fig. 7). This study exhibits the first evidence for glucagon-mediated regulation of leptin expression in lower vertebrates, and may provide new insight into leptin as a mediator in the regulatory network of energy metabolism in the fish model.

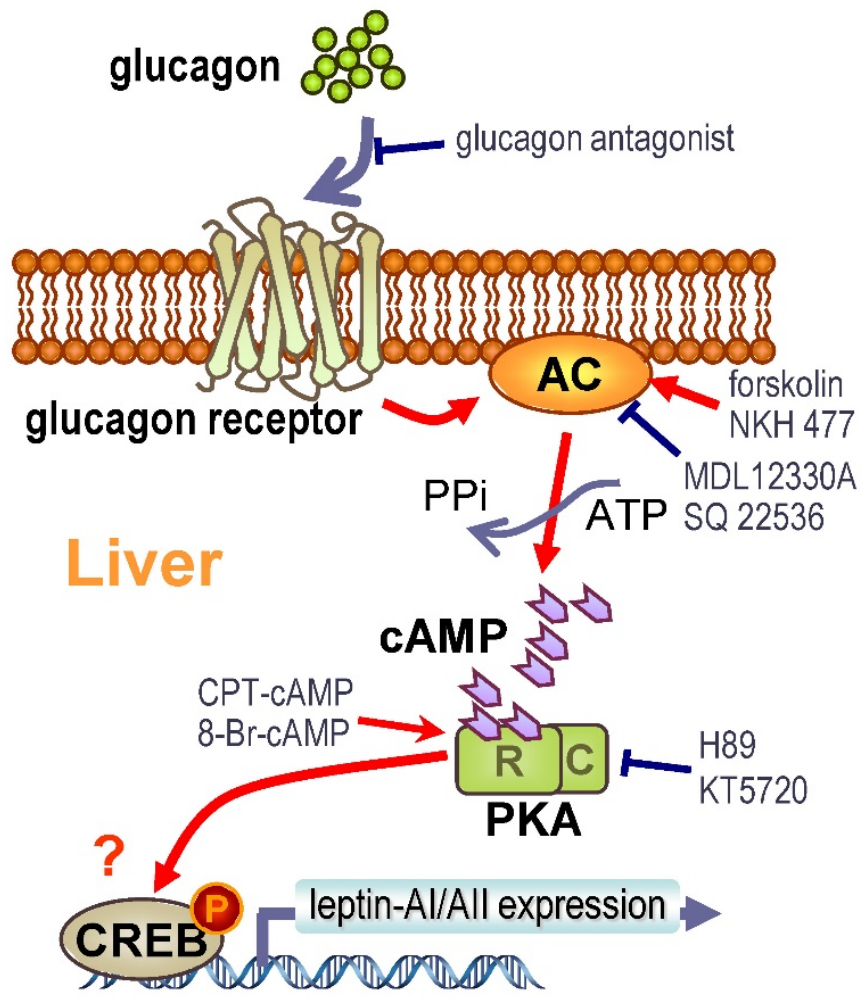

Figure 7. Working model for the signal transduction mechanism of glucagon-induced leptin-AI and leptin-All mRNA expression in goldfish hepatocytes.

\section{Supplementary Material}

Supplementary data. 1 (Suppl. 1): Amino acid sequences of human glucagon and glucagon antagonist. Supplementary data. 2 (Suppl. 2): Primer sequences and real-time PCR conditions used in this study. Supplementary data. 3 (Suppl. 3): Primer sequences for goldfish leptin-AI, leptin-AII, proglucagon and glucagon receptor transcript detection. http://www.ijbs.com/v12p1544s1.pdf

\section{Acknowledgments}

This study was supported by the National Natural Science Foundation of China (31402279), the Foundation for Distinguished Young Talents in Higher Education of Guangdong, China (2013LYM_0098), the Guangdong Province Program
(2014B030301064), and the Excellent Young Teachers Culturing Projects of Foshan University (FSYQ201417). We also thank Prof. Anderson. O.L. Wong (University of Hong Kong) for supplying conditions for real-time PCR validation.

\section{Author Contributions}

TC and SC conceived of and designed the experiments. AFY, TC, SC, $\mathrm{XJ}$ and $\mathrm{WH}$ performed the experiments. AFY, TC, SC, CHR and FL analyzed the data. TC, $\mathrm{CQH}$ and DST contributed reagents/materials/analysis tools. AFY and TC wrote the paper.

\section{Conflicts of Interest}

The authors declare no conflict of interest.

\section{References}

1. Zhang $Y Y$, Proenca R, Maffei M, Barone M, Leopold L, Friedman JM. Positional Cloning of the Mouse Obese Gene and Its Human Homolog. Nature. 1994; 372: 425-32.

2. Mantzoros CS, Magkos F, Brinkoetter M, Sienkiewicz E, Dardeno TA, Kim SY, et al. Leptin in human physiology and pathophysiology. Am J Physiol-Endoc M. 2011; 301: E567-E84

3. Rosenbaum M, Leibel RL. 20 years of leptin: role of leptin in energy homeostasis in humans. The Journal of endocrinology. 2014; 223: T83-96.

4. Gorissen M, Flik G. Leptin in teleostean fish, towards the origins of leptin physiology. Journal of chemical neuroanatomy. 2014.

5. Maffei M, Halaas J, Ravussin E, Pratley RE, Lee GH, Zhang Y, et al. Leptin levels in human and rodent: measurement of plasma leptin and ob RNA in obese and weight-reduced subjects. Nat Med. 1995; 1: 1155-61.

6. Sinha MK, Caro JF. Clinical aspects of leptin. Vitamins and hormones. 1998; 54: $1-30$.

7. Ahima RS, Prabakaran D, Mantzoros C, Qu D, Lowell B, Maratos-Flier E, et al. Role of leptin in the neuroendocrine response to fasting. Nature. 1996; 382: 250-2.

8. Kolaczynski JW, Considine RV, Ohannesian J, Marco C, Opentanova I, Nyce MR, et al. Responses of leptin to short-term fasting and refeeding in humans A link with ketogenesis but not ketones themselves. Diabetes. 1996; 45: 1511-5.

9. Wang JL, Obici S, Morgan K, Barzilai N, Feng ZH, Rossetti L. Overfeeding rapidly induces leptin and insulin resistance. Diabetes. 2001; 50: 2786-91.

10. Attoub S, Levasseur S, Buyse M, Goiot H, Laigneau JP, Moizo L, et al. Physiological role of cholecystokinin B/gastrin receptor in leptin secretion. Endocrinology. 1999; 140: 4406-10.

11. Giovambattista A, Piermaria J, Suescun MO, Calandra RS, Gaillard RC, Spinedi E. Direct effect of ghrelin on leptin production by cultured rat white adipocytes. Obesity (Silver Spring). 2006; 14: 19-27.

12. Machinal F, Dieudonne MN, Leneveu MC, Pecquery R, Giudicelli Y. In vivo and in vitro ob gene expression and leptin secretion in rat adipocytes: evidence for a regional specific regulation by sex steroid hormones. Endocrinology. 1999; 140: 1567-74.

13. Gambino YP, Perez Perez A, Duenas JL, Calvo JC, Sanchez-Margalet V, Varone CL. Regulation of leptin expression by 17beta-estradiol in human placental cells involves membrane associated estrogen receptor alpha. Biochimica et biophysica acta. 2012; 1823: 900-10.

14. Lee MJ, Wang Y, Ricci MR, Sullivan S, Russell CD, Fried SK. Acute and chronic regulation of leptin synthesis, storage, and secretion by insulin and dexamethasone in human adipose tissue. American journal of physiology Endocrinology and metabolism. 2007; 292: E858-64

15. Wang $Y$, Ali Y, Lim CY, Hong W, Pang ZP, Han W. Insulin-stimulated leptin secretion requires calcium and PI3K/Akt activation. The Biochemical journal. 2014; 458: 491-8.

16. Boni-Schnetzler M, Hauri C, Zapf J. Leptin is suppressed during infusion of recombinant human insulin-like growth factor I (rhIGF I) in normal rats. Diabetologia. 1999; 42: 160-6.

17. Yan AF, Chen T, Chen S, Ren $\mathrm{CH}, \mathrm{Hu} C Q$, Cai YM, et al. Goldfish Leptin-AI and Leptin-AII: Function and Central Mechanism in Feeding Control. International journal of molecular sciences. 2016; 17: 783.

18. Murashita K, Uji S, Yamamoto T, Ronnestad I, Kurokawa T. Production of recombinant leptin and its effects on food intake in rainbow trout (Oncorhynchus mykiss). Comp Biochem Phys B. 2008; 150: 377-84.

19. Friedman JM, Halaas JL. Leptin and the regulation of body weight in mammals. Nature. 1998; 395: 763-70.

20. Kling P, Ronnestad I, Stefansson SO, Murashita K, Kurokawa T, Bjornsson BT. A homologous salmonid leptin radioimmunoassay indicates elevated plasma 
leptin levels during fasting of rainbow trout. General and comparative endocrinology. 2009; 162: 307-12.

21. Trombley S, Maugars G, Kling P, Bjornsson BT, Schmitz M. Effects of long-term restricted feeding on plasma leptin, hepatic leptin expression and leptin receptor expression in juvenile Atlantic salmon (Salmo salar L.). General and comparative endocrinology. 2012; 175: 92-9.

22. Fuentes EN, Kling P, Einarsdottir IE, Alvarez M, Valdes JA, Molina A, et al Plasma leptin and growth hormone levels in the fine flounder (Paralichthys adspersus) increase gradually during fasting and decline rapidly after refeeding. General and comparative endocrinology. 2012; 177: 120-7.

23. Zhang HX, Chen HP, Zhang Y, Li SS, Lu DQ, Zhang HF, et al. Molecular cloning, characterization and expression profiles of multiple leptin genes and a leptin receptor gene in orange-spotted grouper (Epinephelus coioides). General and comparative endocrinology. 2013; 181: 295-305.

24. Chen T, Chen S, Ren C, Hu C, Tang D, Yan A. Two isoforms of leptin in the White-clouds Mountain minnow (Tanichthys albonubes): Differential regulation by estrogen despite similar response to fasting. General and comparative endocrinology. 2016; 225: 174-84.

25. Huising MO, Geven EJW, Kruiswijk CP, Nabuurs SB, Stolte EH, Spanings FAT, et al. Increased leptin expression in common carp (Cyprinus carpio) after food intake but not after fasting or feeding to satiation. Endocrinology. 2006; 147: 5786-97.

26. Tinoco AB, Nisembaum LG, Isorna E, Delgado MJ, de Pedro N. Leptins and leptin receptor expression in the goldfish (Carassius auratus). Regulation by food intake and fasting/overfeeding conditions. Peptides. 2012; 34: 329-35.

27. Ramnanan CJ, Edgerton DS, Kraft G, Cherrington AD. Physiologic action of glucagon on liver glucose metabolism. Diabetes Obes Metab. 2011; 13: 118-25.

28. Yuen TTH, Mok PY, Chow BKC. Molecular cloning of a cDNA encoding proglucagon from goldfish, Carassius auratus. Fish Physiol Biochem. 1997; 17: 223-30.

29. Chow BKC, Moon TW, Hoo RLC, Yeung CM, Muller M, Christos PI, et al. Identification and characterization of a glucagon receptor from the goldfish Carassius auratus: Implications for the evolution of the ligand specificity of glucagon receptors in vertebrates. Endocrinology. 2004; 145: 3273-88.

30. Gagnon J, Anini Y. Glucagon Stimulates Ghrelin Secretion Through the Activation of MAPK and EPAC and Potentiates the Effect of Norepinephrine. Endocrinology. 2013; 154: 666-74.

31. Ehrman MA, Melroe GT, Kittilson JD, Sheridan MA. Regulation of pancreatic somatostatin gene expression by insulin and glucagon. Mol Cell Endocrinol. 2005; 235: 31-7.

32. Cyphert HA, Alonge KM, Ippagunta SM, Hillgartner FB. Glucagon Stimulates Hepatic FGF21 Secretion through a PKA- and EPAC-Dependent Posttranscriptional Mechanism. Plos One. 2014; 9.

33. Kauter K, Ball M, Kearney P, Tellam R, McFarlane JR. Adrenaline, insulin and glucagon do not have acute effects on plasma leptin levels in sheep: development and characterisation of an ovine leptin ELISA. Journal of Endocrinology. 2000; 166: 127-35.

34. Shalev A, Vosmeer S, Keller U. Absence of short-term effects of glucagon-like peptide-1 and of hyperglycemia on plasma leptin levels in man. Metabolism. 1997; 46: 723-5.

35. Denver RJ, Bonett RM, Boorse GC. Evolution of Leptin Structure and Function. Neuroendocrinology. 2011; 94: 21-38.

36. Meyer A, Van de Peer $Y$. From $2 R$ to $3 R$ : evidence for a fish-specific genome duplication (FSGD). BioEssays : news and reviews in molecular, cellular and developmental biology. 2005; 27: 937-45.

37. Gorissen M, Bernier NJ, Nabuurs SB, Flik G, Huising MO. Two divergent leptin paralogues in zebrafish (Danio rerio) that originate early in teleostean evolution. Journal of Endocrinology. 2009; 201: 329-39.

38. Prokop JW, Duff RJ, Ball HC, Copeland DL, Londraville RL. Leptin and leptin receptor: analysis of a structure to function relationship in interaction and evolution from humans to fish. Peptides. 2012; 38: 326-36.

39. Shpilman M, Hollander-Cohen L, Ventura T, Gertler A, Levavi-Sivan B. Production, gene structure and characterization of two orthologs of leptin and a leptin receptor in tilapia. General and comparative endocrinology. 2014; 207: 74-85

40. Ronnestad I, Nilsen TO, Murashita K, Angotzi AR, Moen AGG, Stefansson SO, et al. Leptin and leptin receptor genes in Atlantic salmon: Cloning, phylogeny, tissue distribution and expression correlated to long-term feeding status. General and comparative endocrinology. 2010; 168: 55-70.

41. Copeland DL, Duff RJ, Liu Q, Prokop J, Londraville RL. Leptin in teleost fishes: an argument for comparative study. Frontiers in physiology. 2011; 2: 26.

42. Kurokawa T, Uji S, Suzuki T. Identification of cDNA coding for a homologue to mammalian leptin from pufferfish, Takifugu rubripes. Peptides. 2005; 26: 745-50.

43. Douros JD, Baltzegar DA, Breves JP, Lerner DT, Seale AP, Gordon Grau E, et al. Prolactin is a major inhibitor of hepatic Leptin A synthesis and secretion: studies utilizing a homologous Leptin A ELISA in the tilapia. General and comparative endocrinology. 2014; 207: 86-93.

44. Unson CG, Wu CR, Fitzpatrick KJ, Merrifield RB. Multiple-Site Replacement Analogs of Glucagon - a Molecular-Basis for Antagonist Design. J Biol Chem. 1994; 269: 12548-51.

45. Wolf K. Citation-Classic - Physiological Salines for Fresh-Water Teleosts. Cc/Agr Biol Environ. 1986: 20-

46. Askari H, Liu J, Dagogo-Jack S. Hormonal regulation of human leptin in vivo: effects of hydrocortisone and insulin. International journal of obesity and related metabolic disorders : journal of the International Association for the Study of Obesity. 2000; 24: 1254-9.

47. Fanelli CG, Porcellati F, Rossetti P, Bolli GB. Glucagon: the effects of its excess and deficiency on insulin action. Nutrition, metabolism, and cardiovascular diseases : NMCD. 2006; 16 Suppl 1: S28-34

48. Baltzegar DA, Reading BJ, Douros JD, Borski RJ. Role for leptin in promoting glucose mobilization during acute hyperosmotic stress in teleost fishes. The Journal of endocrinology. 2014; 220: 61-72.

49. Chisada S, Kurokawa T, Murashita K, Ronnestad I, Taniguchi Y, Toyoda A, et al. Leptin receptor-deficient (knockout) medaka, Oryzias latipes, show chronical up-regulated levels of orexigenic neuropeptides, elevated food intake and stage specific effects on growth and fat allocation. General and comparative endocrinology. 2014; 195: 9-20.

50. Dalman MR, Liu O, King MD, Bagatto B, Londraville RL. Leptin expression affects metabolic rate in zebrafish embryos (D. rerio). Frontiers in physiology. 2013; 4: 160

51. Michel M, Page-McCaw PS, Chen W, Cone RD. Leptin signaling regulates glucose homeostasis, but not adipostasis, in the zebrafish. Proc Natl Acad Sci U S A. 2016; 113: 3084-9.

52. Kurokawa T, Murashita K. Genomic characterization of multiple leptin genes and a leptin receptor gene in the Japanese medaka, Oryzias latipes. General and comparative endocrinology. 2009; 161: 229-37.

53. Volff JN. Genome evolution and biodiversity in teleost fish. Heredity. 2005; 94 : 280-94.

54. David L, Blum S, Feldman MW, Lavi U, Hillel J. Recent duplication of the common carp (Cyprinus carpio L.) genome as revealed by analyses of microsatellite loci. Mol Biol Evol. 2003; 20: 1425-34.

55. Schlegel A, Gut P. Metabolic insights from zebrafish genetics, physiology, and chemical biology. Cellular and molecular life sciences : CMLS. 2015; 72: 2249-60.

56. Yeung CM, Mojsov $S$, Mok PY, Chow BKC. Isolation and structure-function studies of a glucagon-like peptide 1 receptor from goldfish Carassius auratus: Identification of three charged residues in extracellular domains critical for receptor function. Endocrinology. 2002; 143: 4646-54.

57. Hussain MA, Daniel PB, Habener JF. Glucagon stimulates expression of the inducible cAMP early repressor and suppresses insulin gene expression in pancreatic beta-cells. Diabetes. 2000; 49: 1681-90.

58. Albalat A, Gomez-Requeni P, Rojas P, Medale F, Kaushik S, Vianen GJ, et al. Nutritional and hormonal control of lipolysis in isolated gilthead seabream (Sparus aurata) adipocytes. Am J Physiol-Reg I. 2005; 289: R259-R65.

59. Albalat A, Gutierrez J, Navarro I. Regulation of lipolysis in isolated adipocytes of rainbow trout (Oncorhynchus mykiss): The role of insulin and glucagon. Comparative Biochemistry and Physiology a-Molecular \& Integrative Physiology. 2005; 142: 347-54. 